\title{
Field evaluation of different wheat-alien amphiploids in the conditions of the Absheron Peninsula (Azerbaijan)
}

Rahimov R.G.*, Akparov Z.I., Abbasov M.A., Aliyeva A.J., Mehdiyeva S.P. Genetic Resources Institute of ANAS, Baku, Azerbaijan

*email: rahimov.rg@gmail.com

Many wheat-alien amphiploids derived from hybridization of wheat with its wild relatives and considering as bridges for introducing alien genes into wheat cultivars as well as the valuable research material for genetic investigation of many traits. In our study the field trials were carried out to evaluate agronomic performance of the diverse wheat-alien amphiploids during the period of 2016 to 2020 in the conditions of the Absheron Peninsula (Azerbaijan). A set of the 16 wheat-alien amphiploids used in the present study obtained mainly from collections of different countries (USA, Spain, Mexico and Russia) as well as locally and comprised of 6 tritirigia genotypes (T. aestivum / Ag. junceum, T. aestivum / Ag. distichum, T. aestivum / Ag. intermedium, T. aestivum / Ag. ponticum, T. aestivum cv. Chinese Spring / Ag. scirpeum, T. aestivum cv. Chinese Spring / Ag. elongatum), 5 wheat-barley genotypes (HT-621(H. chilense / T. turgidum), HT471 (H. chilense / T. turgidum), Triticum timopheevii subsp. timopheevii / Critesion bogdanii, Bulel (T. turgidum / H. chilense), Aucan (T. turgidum /H. chilense)), 2 wheat-Elymus lines (Triticum sp. / Elymus arenarius, Elymus ciliaris / T. aestivum subsp. aestivum cv. Inayama comugi), 2 secondary triticale genotypes (AD 908, PRAG 244) and a wheat-dasypyrum genotype (T. turgidum / Haynaldia villosa). The aim of this field assessment was to get data on morphological and physiological traits of these amphiploids for their expected use in different hybridization procedures as initial parent material. Stability on morphological and physiological traits were observed in all studied wheat-alien amphiploids except for three genotypes T. aestivum / Ag. distichum, HT471 and T. turgidum / Haynaldia villosa. 